\title{
De los Aspectos Sociales del Desarrollo Económico a la Teoría de la Dependencia: Sobre la gestación de un pensamiento social propio en Latinoamérica
}

\author{
FROM SOCIAL ASPECTS OF ECONOMIC DEVELOPMENT TO DEPENDENCY THEORY. LATIN AMERICA \\ OWN THINKING BEGINNING
}

Dr. Juan Jesús Morales (juanjesusmorales@cps.ucm.es) Grupo de investigación de Sociología en Lengua Castellana, Universidad Complutense de Madrid (Madrid, España)

\begin{abstract}
In the epistemological context of theory transfer and scientific exchanges, the aim of this paper is to indicate the presence of Weberian categories and ideas on dependency theory formulated by Fernando Cardoso and Enzo Faletto. Here we see how the construction of this paradigm was based on some issues, concepts, approaches and orientations of the Weberian research program formulated by José Medina Echavarría to explain Latin American development. We will also consider the contexts of enunciation and reception theories, allowing us to talk about the "sociological school" that was formed in the Social Planning Division of ILPES in mid-sixties, crucial for understanding the history of sociology in Latin America.
\end{abstract}

Keywords: social aspects of economic development, dependency theory, Weberian sociology, sociological school, own thought.

\section{Resumen}

En el contexto de la discusión epistemológica sobre el examen de las transferencias y los intercambios científicos de las teorías, el objetivo de este artículo es señalar la presencia de categorías e ideas weberianas en la teoría de la dependencia formulada por Fernando Cardoso y Enzo Faletto. Aquí veremos cómo la construcción de este paradigma se sustentó en algunos temas, conceptos, enfoques y orientaciones del programa de investigación weberiano formulado por José Medina Echavarría para explicar el desarrollo latinoamericano. También tendremos en cuenta los contextos de enunciación y de recepción de las teorías, lo que nos permitirá hablar de la "escuela sociológica" que se formó en la División de Planificación Social del ILPES a mitad de los años 60, decisiva para comprender la historia de la sociología en América Latina. 
Palabras clave: desarrollo económico, teoría de la dependencia, sociología weberiana, escuela sociológica, pensamiento propio.

\section{Introducción}

La eclosión de la "teoría de la dependencia" como paradigma sociológico se sitúa simbólicamente con la publicación en 1969 del libro Dependencia y Desarrollo en América Latina de Fernando H. Cardoso y Enzo Faletto. La versión preliminar, titulada "Dependencia y desarrollo en América Latina. Ensayo de interpretación sociológica", circuló internamente en el ILPES como documento de trabajo a partir de octubre de 1967. Como bien ha apuntado Fernanda Beigel, ha habido un uso habitual en el campo intelectual latinoamericano del concepto "teoría de la dependencia" como una categoría aglutinadora que unifica lo que, de hecho, constituyó un conjunto de múltiples enfoques analíticos, principalmente porque en su formulación participaron autores de distintos países, con diferentes formaciones teóricas y con diversas perspectivas ideológicas. En este trabajo nos detendremos específicamente en analizar una de las direcciones que tomó el "dependentismo" como fue la "corriente marxista no ortodoxa" representada por Fernando H. Cardoso y Enzo Faletto.

El interés que despierta este pensamiento se puede juzgar por el número de publicaciones que se han dedicado a esta corriente y a sus distintas versiones (si bien ha sido menos frecuente el análisis sobre las fuentes teóricas y científicas que han nutrido a este paradigma). En efecto, los historiadores de la sociología o del pensamiento social han examinado estos escritos desde un punto de vista más crítico o comprometido, concediendo gran importancia a las filiaciones teóricas e ideológicas y soslayando, sin duda, algunos de los conceptos y temas más importantes. Y cuando han realizado este trabajo de revisión ha sido, principalmente, para destacar la inspiración marxista de algunas de sus formulaciones como los esquemas de "imperialismo económico" o "colonias-metrópoli" (González Casanova 1981:86). También se han señalado otras influencias epistemológicas importantes en la teoría de la dependencia como son la tesis centro-periferia de Raúl Prebisch o la dimensión histórico estructural de los trabajos de Celso Furtado. Sin embargo, una de las referencias que menos se ha destacado en estos estudios ha sido el "hilo weberiano" que hay en la versión dependentista formulada por Cardoso y Faletto.

El objetivo de este trabajo, por tal motivo, es señalar cómo la teoría de la dependencia de Cardoso y Faletto hunde algunas de sus raíces en la sociología comprensiva de Max Weber. Una de las reflexiones más interesantes que nos ofrece la discusión epistemológica es el examen de las transferencias culturales y los intercambios científicos de las teorías. Aquí veremos cómo la construcción de este paradigma científico está montado sobre ideas y conceptos existentes en la tradición sociológica del pensamiento cepalino, como fueron los "aspectos sociales del desarrollo económico" de José Medina Echavarría. Especialmente eficaz para este tipo de análisis es la revisión conceptual y temática. Importante en esa cadena de ideas y conceptos fueron, como veremos, las hipótesis de la hacienda y de la "porosidad estructural" de este sociólogo. Estas dos hipótesis son los eslabones principales que comunican el pensamiento weberiano con la gestación de esta versión de la teoría de la dependencia. Bajo esta perspectiva, que reflexiona sobre las transferencias de las teorías sociológicas, observaremos el papel que asumió Medina Echavarría como "mediador" de las ideas e interpretaciones weberianas. El hilo conductor de la narración toma el programa de investigación weberiano que propuso este autor para explicar el desarrollo económico latinoamericano. Un programa de investigación que fue punto de partida, en cuanto a 
temas, conceptos, enfoques y orientaciones epistemológicas, para la génesis y gestación del pensamiento propio formulado por Cardoso y Faletto.

Además tendremos en cuenta los contextos de enunciación y de recepción de las teorías. Ello se debe a que es sumamente necesario situar las aportaciones conceptuales como los cambios epistemológicos en relación a las situaciones intelectuales y sociales concretas, ya que no podemos estudiar las teorías con independencia de los autores. Es muy importante ubicar las ideas en el tiempo donde esas ideas tuvieron lugar. Sin este marco concreto las ideas se caen. En este sentido, debemos señalar que Cardoso, Faletto y Medina coincidieron en la División de Planificación Social del ILPES de Santiago de Chile a mitad de los años 60. En aquel momento América Latina pasaba por un proceso de modernización que va a cristalizar en el surgimiento del Estado desarrollista y en la configuración de una nueva mentalidad social que correspondería al desarrollismo. El nuevo clima histórico supuso un auténtico desafío para muchas de las ideas sociológicas que se propusieron desde ese organismo internacional. Desde ese marco institucional Medina Echavarría lograría despertar y orientar numerosas inquietudes intelectuales y profesionales de sus dos colaboradores. Como veremos al final del trabajo, todo aquel contexto institucional, social, histórico y político, influyó para la formación de una "escuela sociológica", decisiva para la evolución del pensamiento sociológico en América Latina.

\section{Los contextos de enunciación de las teorías sociológicas. Desarrollo y sociología en la División de Planificación Social del ILPES}

El impulso de la sociología en América Latina tomó fuerza tras la Segunda Guerra Mundial. La demanda modernizadora de los gobiernos latinoamericanos y el papel de los organismos internacionales ayudaron a la promoción de los estudios sociales. La mentalidad desarrollista dio lugar a un proceso de racionalización que no dudó en incorporar las ciencias sociales en los asuntos públicos. En un primer momento la "cuestión social" estuvo ligada a la necesidad del desarrollo económico, teniendo mucha resonancia la teoría centro-periferia de Prebisch, las teorías económicas del "big push" y del crecimiento económico acelerado difundidas por los economistas de la CEPAL. Pero esa conciencia del desarrollo económico se fue trasladando, poco a poco, hacia la urgencia del desarrollo social, entendido como modernización cultural, social y política. La inmediata "obligación" por cumplir ese precepto de modernizarse, asumida por los gobiernos latinoamericanos, trajo consigo cuantiosas permutas que afectaron a la perspectiva de la propia CEPAL. Se fueron tendiendo puentes entre la economía y la sociología.

Las primeras aportaciones de José Medina Echavarría a mitad de los años 50 fueron muy importantes de cara a formular una primera sociología del desarrollo latinoamericano (2). Él fue el primero en hablar en América Latina de los "aspectos sociales del desarrollo económico" para la caracterización más general; de los "supuestos sociales" para los aspectos sociológicos externos, pero imprescindibles, de una teoría económica; de las "condiciones sociales" para los aspectos referidos a la interpretación histórica del proceso económico y, finalmente, de los "obstáculos sociales", para los aspectos culturales y sociales que dificultan el logro de ciertos objetivos económicos programados. Se comenzó a hacer una lectura sociológica de los datos ofrecidos por el economista y, principalmente, se reconoció que en la teoría económica había inserta una teoría sociológica.

La sociología destacó por su valor de "diagnóstico", ofreciéndose como un instrumento útil para las prospectivas económicas y acorde a la voluntad planificadora de los gobiernos latinoamericanos. El papel de la sociología resultó muy importante, porque no sólo se dedicó a las 
tareas de la asesoría técnica, sino que además fue decisiva a la hora de proponer ideas de sociedad a la clase política. La posibilidad de actuar con eficacia en una sociedad suponía, entre otras cosas, tener una imagen de ella y de su funcionamiento; es decir, se requería una teoría. Pareció abrirse un tiempo en el que se relacionó la política con la economía y la sociología, produciéndose una compenetración entre los actores, los procesos investigados y los científicos sociales, que convertían esa síntesis en un auténtico motor de cambio y de transformación social.

En esos años hubo además un clima internacional favorable para los estudios sociológicos que, en el caso latinoamericano, coincidió con el "celo reformista político-social" de la Alianza para el Progreso (Cardoso 1977:30). De esta manera, se produjo una cierta convergencia intelectual, burocrática y financiera entre los Estados Unidos y la CEPAL, compartiendo visiones y perspectivas sobre un determinado desarrollo económico y social. Consecuencia de ese contexto ideológico e histórico fue la fundación en julio de 1962 del Instituto Latinoamericano de Planificación Económica y Social (ILPES). Se creó bajo la égida de la CEPAL y se estableció en Santiago de Chile como proyecto del Fondo Especial de las Naciones Unidas y con un amplio apoyo de los países de la región y de diversos organismos internacionales y privados. Nacía con el objetivo principal de proporcionar, a solicitud de los gobiernos, servicios de capacitación y asesoramiento en América Latina y realizar investigaciones sobre desarrollo y planificación.

La presencia de Medina Echavarría había generado nuevos retos intelectuales y nuevas demandas en la CEPAL que propiciaron con el tiempo la llegada de importantes sociólogos latinoamericanos y extranjeros: Aldo Solari, Jorge Graciarena, Marshall Wolfe, entre otros. Él trabajó de manera muy activa para que la sociología tuviera un peso específico en el nuevo instituto de planificación. Dialogó y negoció con Raúl Prebisch, Secretario de la CEPAL, y con Paul Berthoud, Director de la División de Asuntos Sociales de la CEPAL, para dar forma a la "sección de sociología" que se proyectaba para el ILPES. En un documento de 22 hojas titulado "Sección de Sociología del Desarrollo", les presentó un completo plan de trabajo sobre las competencias, las líneas maestras de la nueva división, sus funciones, sus miembros y los proyectos de investigación. Medina Echavarría consideraba que la División de Asuntos Sociales de la CEPAL había sido un buen prólogo para la inclusión de los estudios sociales en el tema del desarrollo a la hora de redactar monografías y trabajos sobre la planificación educativa, sanitaria o habitacional. Pero entendía que esos "aspectos sociales del desarrollo económico" necesitaban de otra perspectiva distinta al de las políticas sociales, porque únicamente habían representado "un fragmento y sólo un fragmento de lo que exige la consideración sociológica del desarrollo económico de América Latina, si se le quiere conocer en toda su latitud y profundidad". Se necesitaba, desde su punto de vista, un auténtico departamento de investigación y teoría sociológica que tratase los temas sociológicos de una manera unitaria y no fragmentada. En aquel documento señalaba además un número de investigaciones que no se habían realizado en América Latina y que él entendía como imprescindibles para el conocimiento de la realidad social de la región. Entendió la necesidad de acometer "un plan de investigaciones relativamente dominables" y modestas (Medina 1963a:2).

Medina Echavarría asumió la dirección de la nueva División de Planificación Social del ILPES el 30 de noviembre de 1963. Tuvo las facultades necesarias para poder actuar con autonomía a la hora de contar con un mínimo de asistencia personal y financiera para formar un grupo de investigación. Como investigador se incorporó Enzo Faletto, quien había sido reclutado por Medina para la CEPAL en 1959, una vez terminada su maestría en FLACSO. Junto a Faletto también llegó Luis Ratinoff, antiguo alumno de la Universidad de Chile. Los dos ayudaron y colaboraron con 
Medina desde 1960 en la elaboración del informe "Desarrollo social en América Latina después de la guerra", que fue presentado finalmente con el título de "El desarrollo social de América Latina en la post-guerra" en la conferencia de la CEPAL de Mar del Plata del año 1962. En el año 1964 se incorporó Fernando H. Cardoso, como subdirector de la división. Los "aspectos sociales del desarrollo económico" de Medina Echavarría, que en un principio fueron "un conjunto de notas marginales" para ir entrando en el coto cerrado de los economistas (Medina 1971:v), terminaron, al final, por consolidarse institucionalmente en el recién creado ILPES.

\section{El enfoque weberiano de los aspectos sociales del desarrollo económico. Un modelo teórico para el desarrollo económico latinoamericano}

José Medina Echavarría fue intermediario y portador de las ideas sociológicas de Max Weber en América Latina durante más de 30 años. La apropiación de la obra de un autor y la profundización en las claves de la misma es cuestión de tiempo, acorde a la maduración de un proyecto intelectual. Weber fue un autor conocido por el pensamiento social español de las décadas de 1920 y 1930 . Medina llegó a este clásico de la sociología gracias a la mediación de profesores como Adolfo Posada o Fernando de los Ríos, además de disfrutar de estancias universitarias en Alemania que le relacionaron con autores weberianos como Karl Löwith. En la su obra Sociología, Teoría y Técnica, publicada en México en 1941, observamos el peso significativo que Medina concedió a Weber como teórico de la sociología (Medina 1982:59). En 1944 coordinó la traducción y la edición de Economía y Sociedad para el Fondo de Cultura Económica. Ese proceso intelectual continuó en Puerto Rico con sus Lecciones de Sociología de 1948 y culminando con su sociología desarrollista de la que nos ocupamos en este artículo.

Cuando escribió su sociología desarrollista en los años 50 y 60, en una época de crisis ante la redefinición del papel del Estado y de la sociedad latinoamericana, pensó que la problemática del desarrollo económico y social tenía que estar fundamentada en unas teorías sociales y políticas muy consolidadas para poder hablar de aspiraciones individuales, de mejora social, de política o de democracia. Weber le ofrecía un modelo teórico -formulado en su Ética Protestante- sobre las condiciones sociales y "las raíces espirituales de la economía moderna" (Medina 1973:23). La obra del clásico alemán representa la tentativa sociológica más plausible sobre el proceso del desarrollo del capitalismo moderno, y a la vez es el modelo más completo del orden social liberal capitalista tal como existió históricamente. Por tales motivos, Medina Echavarría quiso renovar la perspectiva sobre el desarrollo latinoamericano manejada hasta entonces por los economistas, admitiendo "que junto con el proceso económico de desarrollo se ofrece otro de carácter social" (Medina 1973:37). Y, sobre todo, quiso validar en aquella realidad concreta los presupuestos del análisis weberiano de la "estructura liberal-capitalista de una sociedad" (Medina 1961:28).

El "proyecto weberiano" más maduro de Medina Echavarría consistió entonces en formular un "modelo teórico para el desarrollo económico latinoamericano" (Medina 1961:35). Su investigación partió de la pregunta lanzada por Max Weber de cuáles son las "condiciones sociales" que hacen posible el funcionamiento del sistema capitalista (Medina 1961:28, 1973:12). Pregunta que aplicada al contexto latinoamericano se interpretaría como la búsqueda de los requisitos sociales de la "economía liberal" para América Latina. Medina identificó los "aspectos socio-culturales del desarrollo económico" como "los estímulos o incentivos y otras cuestiones de motivación para la actividad económica" (Medina 1973:113).

Es importante señalar la dificultad para precisar el concepto sociológico "aspectos sociales del desarrollo económico", puesto que Medina (1973:17,37 y 39) también los denomina como "los 
factores político-sociales más importantes que intervienen en el desarrollo económico", como "las cuestiones socio-culturales más importantes que acompañan al desarrollo económico" o como "los supuestos sociales del desarrollo económico".

A partir de ahí se encargó de realizar una profunda revisión sobre el proceso histórico del capitalismo en la región. Sin embargo, su perspectiva epistemológica fue inversa respecto a la sociología anglosajona y también respecto a los clásicos de la sociología. Si cualquier sociólogo anglosajón se preguntaba por "los efectos" del capitalismo, el sociólogo latinoamericano, en cambio, tenía que "averiguar cómo se pone en marcha y funciona un sistema económico según sea el tipo de ambición que sea dable propiciar" (Medina 1973:113). Es decir, el punto de vista era justamente el contrario. Mientras en un caso se trataba de comprender un proceso, en el otro se trataba de inducirlo. En América Latina la preocupación estaba en cómo alterar la sociedad para adecuarla al modelo teórico imaginado. Por tal motivo, a la sociología le correspondió la tarea de explicar cómo había funcionado ese sistema y cuál había sido la disposición económica típica del capitalismo latinoamericano.

Efectivamente, Medina asignó un papel fundamental a los aspectos sociales como "obstáculos culturales y sociales" del desarrollo económico. Para él "la vigencia de determinados valores y la existencia de ciertas actitudes, usos y tradiciones" condicionaban la economía latinoamericana (Medina 1973:3). En su opinión, había que conocer, saber cómo operan y cuáles eran los efectos de estos obstáculos. Por tal motivo, su modelo teórico fue propuesto desde una dimensión histórica y con un contenido en el que destacan dos argumentos conceptuales y temáticos fundamentales: la hipótesis de la hacienda y la hipótesis de la "porosidad estructural". Estamos ante dos de las fundamentaciones teóricas que más interés despertaron en la economía y en la sociología latinoamericana, siendo asimiladas en distintos contextos culturales y políticos.

Para Medina Echavarría la hacienda fue la pieza clave en el proceso histórico y modernizador de América Latina. La hacienda caracterizó a la región como predominantemente agraria, pero sobre todo, fue una institución social que resistió a distintos embates transformadores: el fracaso de las reformas agrarias del siglo XVIII o las tendencias desamortizadoras del siglo XIX son un buen ejemplo. La capacidad de mudanza y la habilidad de permanecer perenne al cambio de la estructura socioeconómica latinoamericana se explica por la persistencia cultural y social de la hacienda. En ella se definieron históricamente los valores, las normas, los medios sociales, o la distribución de los papeles sociales. Este sociólogo presenta así una teoría de la hacienda basada, en última instancia, en cómo esta institución social logró cumplir una importantísima función económica, socializadora, cultural y política. He aquí la esencia de su punto de vista: "La estructura social de América Latina mostró por largo tiempo en todos sus entresijos la capacidad modeladora de una institución fundamental: la de la hacienda. Toda la historia económica, social y política de América Latina es en buena parte la historia de la consolidación y transformaciones de esa unidad económica-social. Y el relato del ocaso de la estructura tradicional se confunde por consiguiente con la del lento declinar de esa vieja organización. Ocaso y no extinción, desde luego, pues todavía persisten tanto su presencia como sus influjos" (Medina 1976:53).

Según Medina Echavarría el gran logro de la hacienda había sido esa persistencia en su capacidad modeladora de la estructura social, prolongada hasta la edad contemporánea. Este proceso fue resultado de la interacción de distintos grupos y clases sociales, que tuvieron en común un modo de relación que les fue propio y que, por tanto, tenían intereses y valores distintos, cuya oposición, conciliación o superación determinó la estructura sociopolítica y el sistema económico de América 
Latina. Sin duda alguna asistimos a una excelente lectura sociológica de la historia económica y política de la región, en la que este sociólogo supo perfilar la modelación del capitalismo periférico y sus complejas fuerzas sociales que presionaban a la hora de reproducir y perpetuar la estratificación social como a la hora de extender las pautas de consumo, antes reservadas a las minorías privilegiadas.

Desde esos mismos parámetros Medina Echavarría situó su novedoso concepto de "porosidad estructural". La hacienda fue el soporte fundamental de la sociedad tradicional latinoamericana, pero sus componentes culturales seguían manifestándose en los años 60 , a pesar de su declive por el proceso capitalista e industrial. No se lograba poner en marcha el "proceso económico deseado" ante la falta de acuerdo entre los intereses económicos y sociales de la ideología desarrollista, de clara aspiración nacional, y los intereses particulares de la minoría latifundista (Medina 1962:71). Ante aquella situación, Medina Echavarría lanzó la hipótesis de que la peculiaridad estructural de América Latina se debía a la permeabilidad al cambio de la sociedad tradicional. El concepto de "porosidad estructural", como hipótesis de la realidad latinoamericana y como un modelo de interpretación teórica, fue escrito por Medina para el documento de trabajo de la CEPAL "El desarrollo social de América Latina en la postguerra" de 1963. Este estudio fue preparado por el sociólogo español en colaboración con Luis Ratinoff y con Enzo Faletto, y presentado como documento de la Secretaría de la CEPAL al Décimo período de sesiones, realizado en Mar del Plata, Argentina, en 1963.

Al respecto de esta hipótesis, este autor prolongaba su programa de investigación weberiano sobre las claves económicas, sociales y políticas de la modernización latinoamericana: "La hipótesis que se formula en este trabajo es que la estructura 'tradicional' ha sido relativamente permeable y que esa porosidad ha permitido absorber los elementos de 'modernidad' que necesitaba sin quebrar por eso su estructura misma... Quizá por resonancia difusa de una teoría weberiana -la disolución de las sociedades tradicionales ante el ataque de revoluciones racionales o carismáticas-, se ha imaginado a las sociedades tradicionales como cáscaras, más o menos endurecidas, capaces sólo de resistir o de quebrarse en añicos. Lo cierto es que las sociedades tradicionales han resultado ser más o menos flexibles y capaces muchas veces de asimilar elementos en extremo racionales en algunos de sus puntos, sin perder por ello su fisonomía... Su 'estructura tradicional', lejos de haber sido rígida e impenetrable, ha tenido la porosidad suficiente para modernizar buena parte de sus elementos, sin alcanzar por eso una duradera 'modernización' rápida y radical... La sociedad tradicional ha sabido adaptarse, ha sabido asimilar éstos o los otros 'enclaves' de modernidad, pero hoy no es suficiente esa modernización" (Medina 1963b:12).

La "modernización" económica de la hacienda no significó su disolución social y cultural. Al contrario, el sistema de relaciones sociales de la hacienda sobrevivió en cuanto a "modelo de organización del trabajo" y como tal permaneció en "gran parte de la estructura social predominante en las áreas rurales de América Latina hasta 1960". Su baja productividad y su poca inversión tecnológica se debían a principios de dominación y prestigio social. La "herencia de las formas tradicionales" durante el proceso económico posterior a la Segunda Guerra Mundial no había alterado la "estratificación social" (Medina 1963b:32). Y esto sucedió así porque, según la opinión de Medina Echavarría, "la sociedad tradicional pudo defenderse gracias a su permeabilidad, pero al mismo tiempo esa su porosidad tuvo que tolerar la infiltración de numerosos ingredientes modernos". Aquí encontramos, sin duda alguna, el poderoso argumento 
que da cuerpo a su teoría de la porosidad estructural: "la prolongación de la sociedad tradicional no es sino la otra cara de la insuficiencia dinámica del desarrollo económico" (Medina 1963b:85). La permeabilidad al cambio de la sociedad tradicional permitía la coexistencia y la compatibilidad no problemática entre lo viejo y lo actual, entre lo arcaico y lo contemporáneo, entre las "actividades típicamente precapitalistas" y las "actividades capitalistas". Este hecho lo denominó Medina como el "carácter elástico" (1963b:70 y 78) de la ambigüedad estructural en América Latina. En esa porosidad habría una funcionalidad: el sector evolucionado extrae del arcaico los elementos necesarios para poder desarrollarse. De esta manera, la porosidad estructural era el gran "obstáculo" en el "camino del desarrollo", por el "hecho de su perduración" impide "la plena modernización y la transformación completa de las estructuras sociales" (Medina 1963b:83).

La industrialización basada en la sustitución de importaciones no había conseguido modificar la estructura del poder tradicional. Incluso parecía que ese proceso económico había reforzado y consolidado las posiciones estratégicas de dominio social de la estructura hacendística. La cultura política latinoamericana, enraizada en la hacienda, podía caracterizar al Estado moderno y desarrollista a partir de prácticas extendidas en la ciudad como las del clientelismo, el compadrazgo o el paternalismo, contradictorias ellas con el proceso de modernización. Por tal motivo, Medina se refirió a la imposibilidad de aplicar el paradigma weberiano en aquella realidad, acabando por centrar todo el modelo teórico en "el elemento externo fundamental" que sería justamente el Estado y la acción planificadora, muy en la línea del pensamiento cepalino clásico. Las condiciones sociales del desarrollo capitalista en la región aludían a la inexistencia de una competencia económica perfecta, traducida en la ausencia de una plena libertad de mercado. Esta situación obligó al Estado latinoamericano a dejar de ser neutral y le llevó a intervenir regulando la actividad económica o participando directamente en ella.

Se trata, en resumen, de un modelo teórico elaborado durante años, de difícil y variada comprensión, pero, sobre todo, destinado a pensar unas sociedades en permanente cambio. Medina demostró con estas hipótesis de la hacienda y de la porosidad estructural la singularidad del subdesarrollo latinoamericano. Su perspectiva histórica sobre este tema fue la que le hizo hablar de un "pensamiento propio". Entendió que "pensar por cuenta propia" era pensar "desde dentro de los problemas que nos son peculiares y que se reconozcan como los más importantes y decisivos". Y el problema por excelencia era obviamente el desarrollo económico, que a la vez debía ser, según el punto de vista de este autor, un "núcleo de incitación sociológica" que obligaba "a un mínimo de originalidad". Un pensamiento sociológico que sólo podía ser original "si se inspira y deriva del complejo de cuestiones que arrastra consigo la necesidad de nuestro crecimiento económico" (Medina 1963c:109). Podemos decir que este diagnóstico a favor de un pensamiento sociológico propio fue una de sus ideas-fuerza que más influencia causaron, como veremos a continuación, en Cardoso y Faletto. Medina reflexionó en un período en el que se estaba forjando una "sociología latinoamericana" y para él eso significaba una oportunidad por ir más allá de las modas sociológicas de la teoría de la modernización o del funcionalismo. Los mejores valedores de aquella apuesta de peso terminarían siendo sus dos discípulos del ILPES, a partir del modelo teórico de la dependencia.

\section{La influencia weberiana en la gestación de la teoría de la dependencia}

La presencia de Medina Echavarría en el ILPES fue un activo importante a la hora de generar un conocimiento sociológico propio. Su estudio sobre la situación de América Latina en la posguerra, escrito junto a Faletto y Ratinoff, fue muy importante porque "por primera vez surgió una visión 
global de América Latina a partir de su perspectiva social" (Rego 2007:198). Aquella obra fue semilla del documento "El Proceso de Desarrollo en América Latina: Hipótesis para una interpretación sociológica", que Cardoso hizo circular en 1965 entre sus compañeros y en el que introduce por vez primera la palabra dependencia. Como asegura José Luis Reyna (2007:4), "el impacto que tuvo este documento fue enorme, pues su enfoque tenía como base el análisis integrado de los procesos de desarrollo económico, el cambio social y los aspectos políticos". La aparición del término dependencia - "un concepto básico de la explicación de América Latina", según Rolando Franco (2007:101)- simbolizaba una nueva perspectiva a la hora de encarar teóricamente el análisis de los problemas de la región. Estas ideas "dependentistas" fueron madurando con el tiempo y gracias a la sinergia de aquel movimiento sociológico e intelectual que se concentró en la División de Planificación Social del ILPES.

La influencia de Medina Echavarría en la obra Dependencia y Desarrollo en América Latina de Cardoso y Faletto -y en posteriores trabajos de estos autores- estuvo situada en un plano conceptual, metodológico y operativo. Fue muy importante el enfoque histórico-estructural que los dos sociólogos latinoamericanos asumieron. Estos autores, al igual que Medina, concibieron al desarrollo como un "proceso histórico" y para comprenderlo se requería el estudio de las relaciones estructurales conformadas a lo largo de ese proceso: "Se requiere, por consiguiente, y ellos es fundamental, una perspectiva que, al poner de manifiesto las mencionadas condiciones concretas -que son de carácter estructural- y al destacar los móviles de los movimientos sociales objetivos, valores, ideologías- analice aquéllas y éstos en sus relaciones y determinaciones recíprocas... Ello supone que el análisis sobrepase el aporte de lo que suele llamarse enfoque estructural, reintegrándolo en una interpretación hecha en términos de 'proceso histórico'" (Cardoso y Faletto 1971:18).

El desarrollo no podía ser el resultado espontáneo de la acción de las leyes de mercado, sino que era un proceso histórico de transformación de las relaciones estructurales y sociales. Cardoso y Faletto reconocieron el carácter estructural de la dependencia, ligando en su estudio lo político, lo histórico, lo económico y lo cultural. El análisis de la hacienda de Medina y su visión weberiana sobre los "obstáculos sociales y culturales" del desarrollo económico son vitales aquí para entender la importancia que concedieron los dos sociólogos latinoamericanos a las estructuras de dominación política y de explotación económica y social en América Latina. En aquella hipótesis Medina reconocía, recordémoslo, cómo el desajuste económico tiene su origen en el desajuste social y en la reproducción cultural de esas situaciones de dominación o "dependencia". Estos autores, como reconocía Cardoso, aceptaron, junto con Medina, que existía una "historia, y por lo tanto, una dinámica, propia de cada situación de dependencia" (Cardoso 1970:405). Asumir esta categoría de "situación de dependencia" significaba reconocer, primero, la conformación peculiar e histórica del subdesarrollo periférico y admitir, después, la importancia de la cultura como parte relevante de ese proceso.

El desarrollo, según lo entendieron Cardoso y Faletto, no era un hecho económico en sentido restringido. En él había grandes tensiones entre la cultura, la estructura social, las clases, los Estados y los sistemas de producción. Sin embargo, estos autores incluyeron el examen de los procesos de expansión de la economía internacional y la forma de cómo América Latina se fue incorporando históricamente al orden capitalista internacional. Existía, por tanto, una voluntad de superar epistemológicamente la perspectiva endógena de Medina Echavarría, quien siempre 
entendió que el desarrollo económico y social era más una cosa de factores internos que de factores externos.

Ese deseo lo expresaban Cardoso y Faletto de la manera que sigue: "El reconocimiento de la historicidad de la situación de subdesarrollo requiere algo más que señalar las características estructurales de las economías subdesarrolladas. Hay que analizar, en efecto, cómo las economías subdesarrolladas se vincularon históricamente al mercado mundial y la forma en que se constituyeron los grupos sociales internos que lograron definir las relaciones hacia fuera que el subdesarrollo supone. Tal enfoque implica reconocer que en el plano político-social existe algún tipo de dependencia en las situaciones de subdesarrollo, y que esa dependencia empezó históricamente con la expansión de las economías de los países capitalistas originarios" (Cardoso y Faletto 1971:23).

Esa "dependencia" respecto a los centros económicos internacionales generó en el interior de los países latinoamericanos la formación y la reproducción de situaciones estructurales de dominación social que fueron surgiendo en distintas etapas históricas: la fase de constitución del Estado nacional y la formación de una burguesía exportadora; la dependencia en la situación de enclave; y la dependencia en la etapa de internacionalización del mercado. Lo que pretendían ambos autores, concretando su análisis, no era hablar "de la dependencia en general, sino de situaciones de dependencia", como vimos anteriormente (Cardoso 1970:411). Con ese concepto insistieron en la posibilidad de explicar los procesos sociales, políticos y económicos nacionales a partir de una perspectiva histórica y estructural de la dependencia. En la propuesta de estos autores se señala una atadura histórica del desarrollo latinoamericano a los condicionantes externos: la dependencia económica a los centros capitalistas limita el ejercicio de la soberanía nacional de los países latinoamericanos. Esta dependencia debilita y disminuye su capacidad de definir sus rutas de crecimiento y reduce drásticamente el rango de opciones nacionales. $Y$, en el otro extremo, esta dependencia económica fortalece la influencia externa sobre los países periféricos.

Cardoso y Faletto muestran cómo la "internacionalización del mercado" ha solidarizado y ha provocado alianzas entre clases sociales que en épocas históricas anteriores eran antagónicas, caso de la burguesía nacional y la burguesía comercial-externa, con clases trabajadoras, etc.: "Resaltamos que la situación actual de desarrollo dependiente no sólo supera la oposición tradicional entre los términos desarrollo y dependencia, permitiendo incrementar el desarrollo y mantener, redefiniéndolos, los lazos de dependencia, sino que se apoya políticamente en un sistema de alianzas distinto del que en el pasado aseguraba la hegemonía externa" (Cardoso y Faletto 1971:164). Ambos autores lo que destacan es que la dependencia al exterior viene de la subordinación y del comportamiento de las clases sociales vinculadas con el nuevo orden capitalista internacional: "Por consiguiente, al considerar la 'situación de dependencia' en el análisis del desarrollo latinoamericano, lo que se pretende poner de manifiesto es que el modo de integración de las economías nacionales al mercado internacional supone formas definidas y distintas de interrelación de los grupos sociales de cada país, entre sí y con los grupos externos" (Cardoso y Faletto 1971:28). En otras palabras, la dependencia económica hacia los centros capitalistas tendría consecuencias en las estructuras sociales de los países periféricos. Entre estos efectos el más visible sería el dominio o la autoridad de unas clases sobre otras según su relación con estos grupos externos. Esta "elasticidad" hacia fuera explicaría en el interior de estos países, por ejemplo, diferencias y desigualdades sociales, distintas demandas y movilizaciones. La 
constatación de esta "elasticidad" estaría detrás de convulsiones sociales, del desempleo, de la exclusión social; fomentaría la ausencia de expectativas en ciertos grupos sociales o favorecería las rigideces clasistas.

Nos atrevemos a señalar cómo los apuntes de Medina Echavarría de la "porosidad estructural" de la sociedad latinoamericana -como rasgo definidor de su composición sociopolítica- fueron muy importantes para el estudio de Cardoso y Faletto. En la siguiente cita comprobamos cómo ambos autores incorporan en su análisis de la dependencia la aportación teórica del sociólogo español: "aunque la 'sociedad tradicional' haya transformado en buena medida su faz económica, con todo, algunos de sus grupos no perdieron el control del sistema de poder, a pesar de haberse visto obligados a establecer un sistema complejo de alianzas con los nuevos grupos aparecidos". De esta suerte, ambos sociólogos señalaron cómo la dependencia de las economías latinoamericanas al mercado internacional afectaba de manera muy manifiesta a las estructuras políticas nacionales a partir de "la trama de relaciones sociales subyacentes" (Cardoso y Faletto 1971:9). Por eso observan que la autonomía política nacional esté "amenazada" no sólo por el condicionante externo, sino también por aquellos "agentes sociales que tienen posiciones estratégicas en el funcionamiento de la sociedad" (Franco 1974:89). Bajo este nuevo enfoque las elites periféricas quedaban caracterizadas como el grupo social que sirve de nexo o puente con los centros capitalistas, prolongando, de esta manera, las situaciones de "dependencia" económica, social o cultural.

La perspectiva de Cardoso y Faletto, por tal motivo, reconocía a los grupos sociales dominantes en América Latina como aquellos grupos que establecen las alianzas con el exterior y que gracias a esas mediaciones han sabido amoldarse a los cambios económicos. Pero no sólo eso, sino que estas elites también eran las encargadas de establecer en la sociedad -a partir de las coaliciones estratégicas y de la subordinación de los distintos grupos y clase sociales- un modo de producción económico compatible con sus intereses y objetivos (Cardoso y Faletto 1971:20). De esta manera, los dos autores postulaban que la superación o el mantenimiento de las barreras estructurales del subdesarrollo dependen más del juego de poder político que de las condiciones puramente económicas. La acción colectiva de cambio social pasaba "por voluntades políticas que hagan factible lo que estructuralmente apenas es posible" (Cardoso y Faletto 1971:166). Esto quiere decir que la orientación que tome el desarrollo o la modernización en los países de América Latina "depende" de la voluntad que le confieran a ese proceso los actores políticos. La situación de dependencia es, en fin, una situación política. Por tanto, es el actor político el que podrá manejar, cortar o superar, las situaciones de dependencia (en esa dualidad interna-externa) y soltar o cortar las amarras que impiden el desarrollo.

La teoría de la dependencia de Cardoso y Faletto trató de ver la amplitud de los procesos económicos internacionales y su incorporación en la estructura social de los países latinoamericanos a partir de los sistemas de alianzas entre las elites dirigentes. Este tema de las alianzas estratégicas del capitalismo periférico había sido planteado por Medina en una serie de investigaciones sobre las elites latinoamericanas llevadas a cabo en la CEPAL y en el ILPES, y en las que participaron Cardoso y Faletto (3). El programa de investigación weberiano de Medina tuvo cabida en actividades empíricas y fue punto de partida -en cuanto a formulación de hipótesis, planteamientos, problemas- para las posteriores contribuciones científicas de estos investigadores. Uno de los argumentos fundamentales de Cardoso y Faletto sobre el que construyeron su versión "dependentista" fue la pregunta weberiana respecto a qué clase debía 
dirigir el cambio social. Ambos dieron mucha importancia a la circulación de las elites, a su calidad y a sus características particulares. Su interés por acentuar el componente histórico de la noción de dependencia, les llevó a indagar sobre la formación original de las elites latinoamericanas. El mero hecho de retomar la categoría "elite" como objeto analítico con el que recorrer la estructura sociopolítica latinoamericana y desde la que poder observar "las nuevas alianzas de mantenimiento de poder", es la muestra más palpable de la herencia dejada por Medina en estos autores (Cardoso y Faletto 1971:155). Cardoso y Faletto compartieron con el sociólogo español la visión de una modernización económica y social sustentada en el papel de una elite dirigente capaz de asumir "los riesgos de la aventura del futuro" (Cardoso 1965:178). Todos ellos se preguntaron sobre la "dirección" del proceso de desarrollo latinoamericano y se encargaron de estudiar los distintos actores implicados en el despegue económico de la región. Pero obviamente con distintos matices y con diferentes objetivos.

\section{Las diferencias epistemológicas. Distintas formas de entender la función social de la sociología}

El nacimiento de la teoría de la dependencia dentro del ILPES significó una superación epistemológica con el pensamiento cepalino original, ya que consiguió incorporar un "análisis de las relaciones internacionales de explotación" que hizo "más consistente y transparente su posición crítica inicial" (Cardoso 1977:15). La versión dependentista de Cardoso y Faletto representó un criticismo sociológico hacia el desarrollismo de la época. La ruptura que plantearon no fue con unas determinadas formas de la sociedad, sino con toda esa "nueva" sociedad desarrollista que estaba emergiendo con fuerza. En consecuencia, para ellos lo nuevo fue un problema social y también un problema teórico-epistemológico: la teoría de la dependencia tenía que ser la continuación de los aportes del desarrollo de la sociología latinoamericana y de sus afluentes y confluentes europeos, que descubren en Medina Echavarría y en los sociólogos contemporáneos clásicos.

Cardoso y Faletto vieron que la obra de Medina les ofrecía un amplio y dinámico mundo de aperturas teóricas, pero no así de cristalizaciones colectivas o políticas. Es normal que le cuestionasen y criticasen, animados por unas opciones epistemológicas y un uso social diferente de la ciencia sociológica. Lo nuevo había que entenderlo en otra semántica. Fueron conscientes de que había que consolidar y superar dialécticamente lo logrado, someter a examen y análisis sus propias proyecciones teóricas. Principalmente esto se reconoce en el esfuerzo que acometieron por integrar las "categorías marxistas y weberianas" a la hora de explicar el desarrollo latinoamericano (Solari et. al. 1976:446). Si Weber les abrió la perspectiva concreta e histórica, Marx supuso la aprehensión crítica. Tuvieron una nueva conciencia social que chocó con el funcionalismo, la sociología científica o los esquemas teóricos de la antigua generación.

El marxismo pasó a ser una fuente teórica predominante en las nuevas generaciones de sociólogos y de científicos sociales. Aquel marxismo englobaba una gran variedad de tendencias, de ortodoxias y heterodoxias de diverso grado, tenía al "joven" y al "viejo" Marx, a neomarxistas como Althusser y Poulantzas, a Marcuse y a la Escuela de Frankfurt, o a Wright Mills, como uno de los más importantes renovadores de la teoría marxista. También hubo un auge extraordinario de Gramsci. El marco institucional del ILPES recogió la crisis del "paradigma científico" de la sociología latinoamericana de aquellos años. En concreto, la primera gran diferencia epistemológica entre los "aspectos sociales del desarrollo económico" de Medina Echavarría y la teoría de la dependencia de Cardoso y Faletto fue el peso desigual que concedieron a Marx y al marxismo. La preferencia de Medina Echavarría por Weber, como su referente teórico principal, se debió a que en el clásico 
alemán halló los fundamentos suficientes para teorizar sobre el capitalismo moderno. Era lo más lógico, toda vez que la faceta fundamental de Marx es su teoría económica, mal que nos pese a los sociólogos, que siempre barremos para casa en contra de la voluntad explícita del autor.

Cardoso y Faletto, por su parte, no permanecieron impasibles ante su tiempo. Estuvieron muy influidos por el contexto social y político de Chile y de la América Latina de los "largos" años 60, que se inician con la Revolución cubana y se cierran con el golpe de Estado de Pinochet en 1973 (Faletto 1999:123). Entre medias todo un cúmulo de experiencias vividas, como la dictadura militar en Brasil o el movimiento estudiantil chileno iniciado con la Reforma Universitaria de 1967. El marxismo y el programa de investigación sociológica del materialismo histórico lo utilizaron como un símbolo de identidad frente a la generación anterior de profesores e investigadores. Pero también es cierto que Cardoso y Faletto atacaron su coyuntura desde la ciencia. El caso es que este pensamiento "dependentista" surgió como una "contra-teoría" (Cardoso 1981:33). Por un lado, "estos estudios procuraron profundizar algunos elementos ya contenidos en las explicaciones de la CEPAL y explicar tanto la cuestión del capital extranjero como la del fundamento de clases del desarrollo capitalista" (Cardoso 1977:36). Y, por otro lado, criticaron también las formulaciones "surgidas de la izquierda tradicional, que seguía viendo en la alianza 'latifundio-imperialismo' el gran enemigo del desarrollo" (Cardoso 1981:35). De esta manera, el enfoque de la dependencia conquistó fuerzas como una contra teoría -e incluso como una "contra ideología"- para criticar simultáneamente los enunciados cepalinos y los enunciados marxistas más simplistas y radicalizados. La pretensión de aquella versión dependentista era explicar la subordinación de los países latinoamericanos a los procesos capitalistas internacionales.

A partir de esa consideración, el debate giró entonces en facetas más ideológicas que teóricas. Aunque vale la pena mencionar que hubo una distancia efectiva entre Cardoso y Faletto respecto a otros dependentistas, sobre todo en lo que tenía que ver con la validez del principio de la revolución, ya que para estos no fue una posibilidad. Su propuesta estuvo más dedicada a comprender el "imperialismo actual", visto como un capitalismo avanzado y más complejo. La inclinación política de estos dos autores se debía, según confesaría Faletto tiempo después, a esas "expectativas de democratización, de cambios económicos y de ampliación de los procesos de incorporación y de participación política y social" que "no lograban cumplirse; en parte porque el propio proceso de cambio generaba conflictos que los grupos de poder no estaban dispuestos a asumir -dado que afectaban sus posiciones de privilegio-, o porque los gobiernos que habían asumido la nueva conducción política, tensionados por las pugnas sociales, se mostraban incapaces de resolverlas, defraudando las esperanzas puestas en ellos" (Faletto 1999:121). Y aquí encontramos la segunda gran diferencia epistemológica y teórica entre Medina y sus dos colaboradores respecto a las "expectativas de democratización" para América Latina.

Medina Echavarría, claro está, perteneció a una generación distinta que la de Cardoso y Faletto, con una forma diferente de entender el compromiso político del desarrollo económico y con una idea distinta de la función social de la sociología. Muchos jóvenes sociólogos latinoamericanos entendieron a la sociología, no como una ciencia analítica, sino como una ciencia práctica y como un instrumento capaz de modificar la realidad social y de generar experiencias políticas. Incluso la vieron como un "artilugio" para luchar contra las injusticias sociales. A esta "disputa generacional" se refirió el propio Medina en su trabajo de 1970 "Los supuestos políticos de una crítica económica", que constituyó una respuesta crítica al famoso libro de sus discípulos. 
En aquel texto reconocía que la "primera generación desarrollista" -a la que él perteneció- manejó un programa de ideas y de acción a través la planificación democrática. Aquella generación, como reconoce Medina, asumió una "protesta moral" y también trató de manifestar "una esperanza sobre la posibilidad de superar alguna vez circunstancias éticamente intolerables". Indicaba, de esta manera, que la condición de subdesarrollo, como una situación injusta "que divide a los países y a los hombres en sectores cada vez más distanciados en sus niveles de vida", solamente podía ser superada a partir de la formula democrática. Esta "protesta moral" era una crítica dirigida a la "segunda generación desarrollista" que él reconoce en aquellos jóvenes sociólogos y que, desde su punto de vista, acentuaban "de una u otra manera la causalidad externa del hecho de la 'dependencia'" (Medina 1970:197). Para él la importancia del asunto de la dependencia y del subdesarrollo radicaba en los supuestos políticos internos de cada país. También se trataba de hacer ver a esa segunda generación, distraída en esa causalidad externa, que algo más importante y mediato era fortalecer el sistema político y el patrimonio democrático. La crítica de Medina recordaba el valor inmaterial de la democracia en el continente latinoamericano.

Al tiempo de formular su teoría de la dependencia, Cardoso y Faletto hicieron un balance muy equilibrado del papel que Medina Echavarría desempeñó en la divulgación del valor sociológico de la democracia. La crítica que formularía años después Cardoso (1981:41) a la generación de autores dependentistas tenía que ver con la poca preocupación que mostraron en sus escritos y en sus trabajos sobre el tema de la democracia. Fue una variable que se marginó. Se primó el desarrollo, la modernización, la justicia social, la revolución, pero se olvidó de disertar sobre algo tan importante como era el medio para llevar a cabo eso: el instrumento democrático. La historia ha terminado por demostrar que la lucha de clases de los dependentistas era insuficiente sin el apoyo de un Estado democrático.

Si en algún momento Cardoso y Faletto sobreestimaron las causas y los factores del subdesarrollo económico latinoamericano y privilegiaron en sus análisis las fuerzas externas del mismo, no dudaron en ir añadiendo en su perspectiva sociológica aspiraciones no materialistas como la participación social o como los valores de representación cultural y política. Con el paso del tiempo estos autores actualizaron y dieron continuidad a las ideas democráticas de Medina Echavarría. Por ejemplo, Cardoso (1982:119) no dudó en reconocer la importancia de la reflexión del sociólogo español sobre la democracia en América Latina, comparable a la realizada por Tocqueville sobre la democracia en América del Norte. Faletto (1980:2), por su parte, empezó a preocuparse por "encontrar fórmulas renovadoras de vida y cultura, que siempre estuvieran ligadas... a la posibilidad del despliegue de la libertad en una convivencia democrática". El discurso idealista de Medina Echavarría se fue haciendo más palpable en Cardoso y Faletto en la medida en que la democracia en la región se identificó, más que como problema, como esperanza (Lechner).

\section{El significado de un pensamiento sociológico propio. A modo de conclusión}

Desde un punto de vista epistemológico hemos comprobado la recepción de la corriente weberiana en la teoría de la dependencia formulada por Fernando H. Cardoso y Enzo Faletto. Hemos observado además que estos dos autores no distorsionaron aquella tradición sociológica, incorporando en la interpretación del desarrollo latinoamericano y sus situaciones de dependencia el estudio de las elites. Al principio de exponer su análisis no asumieron las condiciones de la democracia y de la economía liberal en el sentido definido por Max Weber y transmitido por José Medina Echavarría. Tiempo después, y con la llegada de las dictaduras militares en la región, entendieron, sin embargo, que la modernidad en América Latina había sido una modernidad 
restringida a ciertos sectores de la población. Por tal motivo, no dudaron en manifestar la importancia de las aportaciones de Medina sobre la formación histórica de los sistemas de autoridad y de legitimidad, señalados en sus hipótesis de la hacienda y de la porosidad estructural. A partir de ese reconocimiento, Cardoso y Faletto comprendieron que el auténtico desarrollo social en América Latina pasaba por una modernización más cultural y política que económica, sustentada en un Estado democrático, reformista y planificador. En cambio, siempre tuvieron muy presente la perspectiva histórica en los estudios sociales que Medina les aportó.

Justamente ese nexo histórico -que más les unió en el plano epistemológico y teórico- es el que nos permite hablar de una "escuela sociológica" (Di Filippo 2007). En la División de Planificación Social del ILPES se generó un ambiente propicio y proclive para el debate y el intercambio de conocimiento que tuvo como resultado la gestación de la teoría de la dependencia como el primer discurso sociológico en América Latina que podemos llamar como propio. La experiencia intelectual surgida en aquel organismo internacional durante la segunda mitad de los años 60 representó un período muy concreto y significativo de la historia de la sociología latinoamericana. Alrededor de estos sociólogos del ILPES se generó un auténtico programa de investigación, en el que trabajaron bajo unas mismas ideas, con un mismo tema (la génesis del desarrollo capitalista en América Latina y sus implicaciones sociales) y compartiendo una misma perspectiva latinoamericana. Ello supuso, en cierto sentido, una forma distinta de hacer sociología respecto a la que se hacía en el mundo anglosajón. Se apostó por una sociología concebida desde el enfoque "puramente analítico hasta el más histórico y concreto", en vez de por una "sociología de oficina", saturada de estadísticas, datos, etc. (Medina 1973:xii). No se revelaron únicamente contra el empirismo abstracto y su formulación teórica-metodológica, sino que además discutieron y rechazaron la "traslación mecánica de las teorías existentes" en Europa o Estados Unidos (Faletto 1996:193). El resultado más destacable de aquel intercambio intelectual es que la sociología latinoamericana se piensa desde entonces en relación a la historia y a su dimensión regional.

Aquellos años sirvieron, no obstante, para borrar las fronteras nacionales de la sociología latinoamericana; para trabajar desde distintas teorías y perspectivas sociológicas, pero compartiendo el vaso conductor del desarrollo económico y social; para avanzar en la investigación empírica y teórica de la región, progresando con la ayuda de otras ciencias sociales, principalmente de la economía y de la historia. Se estableció entonces una visión "transhistórica" de la sociología que sigue siendo vigente. El vocabulario sociológico, por lo menos en América Latina, ha quedado muy ligado a los determinantes históricos y estructurales, y a la forma en que se van integrando en el pensamiento sociológico. La sociología, como ciencia que aspira a sistematizar y a ofrecer conceptos, a la hora de construirlos tiene que tener en cuenta la historicidad tanto de sus conceptos como de la propia sociedad.

Cardoso, Faletto o Medina cambiaron la forma de pensar las construcciones de la propia sociología latinoamericana. Han obligado a que el estudioso o sociólogo latinoamericano deba acudir a la historia. Aquellos nombres entendieron que para hacer teoría sociológica en América Latina o formular conceptos analíticos no se podía prescindir de la historia y de la dimensión puramente latinoamericana. Y eso sigue siendo actualmente muy importante, porque las teorías desarrolladas por los latinoamericanos en los últimos 50 años tienen que ser validadas mirando a la historia. Porque cuando la historia cambia, las teorías ya no pueden ser las mismas. 


\section{Notas}

(1) No conviene olvidar que el enfoque de los "aspectos sociales del desarrollo económico" también se explica por la influencia en Medina de sus compañeros economistas, caso de Prebisch o Furtado. Recordemos que este sociólogo español fue reclutado de la Universidad de Puerto Rico en 1952 por Raúl Prebisch, porque con él se quería abrir el tema del desarrollo económico a la perspectiva sociológica. Pero por problemas de cargos administrativos en la CEPAL, se le incorporó como editor, dada su experiencia en esta tarea. No existía "oficialmente" el puesto de sociólogo y se inventaron una argucia burocrática para incorporarle. Prebisch, como recordaba, no tuvo otra manera de traerlo: "Pasaron algunos años, se creó la Comisión Económica para América Latina, y un buen día mi viejo y querido amigo Víctor Urquidi, me dijo: 'Creo que si Ud. le ofrece a don José Medina ir a Santiago, aceptará'. Le ofrecí y aceptó. Tuvimos un pequeño problema, que no tardó en superarse. ¿Cómo llevar un sociólogo eminente a esta Comisión Económica, en épocas en que se vigilaba celosamente cualquier tentativa nuestra de extralimitarnos? Inventamos la fórmula de ocuparnos de los aspectos sociales del desarrollo económico y bajo esa fórmula empezó don José Medina a trabajar entre nosotros" (Prebisch 1982:15).

(2) Nos referimos, en concreto, a los siguientes documentos de trabajo de la CEPAL: Las condiciones sociales del desarrollo económico, presentado al sexto período de sesiones de la CEPAL en Bogotá en agosto-septiembre de 1955 como Informe preliminar sobre el estudio "Las condiciones sociales del desarrollo económico". Tres aspectos sociológicos del desarrollo económico de 1955 (en colaboración con Zygmunt Slawinski) y El problema social en el desarrollo económico de Bolivia de 1956.

(3) Medina Echavarría dirigió en 1963 una investigación sobre "El empresario industrial en América Latina", en la que participó Cardoso con un trabajo sobre el empresariado brasileño. También colaboraron en la investigación Eduardo A. Zalduendo, Guillermo Briones y Aarón Lipman (Documento CEPAL, E/CN.12/642). Además nos consta que durante 1966 Cardoso y Faletto, mientras escribían su libro Dependencia y Desarrollo en América Latina, trabajaron estrechamente junto sus compañeros sociólogos del ILPES en la investigación, dirigida por Medina Echavarría, sobre "Las elites urbanas en América Latina". Esta investigación fue presentada en el Sexto Congreso Mundial de Sociología, celebrado en Evian, entre el 4 y el 11 de septiembre de 1966. Medina se encargó de la "Introducción", Enzo Faletto escribió un capítulo sobre "La ciudad indiana y los grupos sociales" y Cardoso sobre "Las elites empresariales". Junto a ellos participaron otros miembros del ILPES como Francisco Weffort, Adolfo Gurrieri o Edelberto Torres Rivas.

\section{Bibliografía}

Cardoso, F. H. 1965. Análisis sociológicos del desarrollo económico. Revista Latinoamericana de Sociología 2: 178-199.

Cardoso, F. H. 1970. Teoría de la dependencia o análisis de situaciones concretas de dependencia. Revista Latinoamericana de Ciencia Política 3: 400-419.

Cardoso, F. H. 1977. La originalidad de la copia: la CEPAL y la idea de desarrollo. Revista de la CEPAL 4: 7-40.

Cardoso, F. H. 1981. El desarrollo en capilla. En. R. Franco. Planificación Social en América Latina y el Caribe. Santiago de Chile: ILPES, UNICEF, pp. 25-55. 
Cardoso, F. 1982. La persistencia democrática. En: F. H. Cardoso, E. Faletto, J. Graciarena (et al.). Medina Echavarría y la sociología latinoamericana. Madrid: Ediciones Cultura Hispánica, Instituto de Cooperación Iberoamericana, pp. 113-125.

Cardoso, F. H. y Faletto, E. 1971. Dependencia y desarrollo en América Latina. México: Siglo XXI.

Di Filippo, A. 2007. La Escuela Latinoamericana del Desarrollo. Cinta moebio 29: 124-154.

Faletto, E. 1980. Los temas de democracia y libertad en José Medina Echavarría. Vigencia y contextos. Programa FLACSO, Documento de trabajo 94.

Faletto, E. 1996. La CEPAL y la sociología del desarrollo. Revista de la CEPAL 58: 191-204.

Faletto, E. 1999. Los años sesenta y el tema de la dependencia. Revista de Sociología 13: 119-126.

Franco, R. 1974. Veinticinco años de sociología latinoamericana. Un balance. Revista Paraguaya de Sociología 30: 57-92.

Franco, R. 2007. La FLACSO clásica (1957-1973). Vicisitudes de las ciencias sociales latinoamericanas. Santiago de Chile: FLACSO-Catalonia.

González Casanova, P. 1981. Corrientes críticas de la sociología contemporánea. Economía de América Latina 6: 83-92.

Medina Echavarría, J. 1961. Las relaciones entre las instituciones sociales y las económicas. Un modelo teórico para América Latina. Boletín Económico de América Latina 1: 27-39.

Medina Echavarría, J. 1962. Aspectos sociales del desarrollo económico de América Latina Vol I. París: UNESCO.

Medina Echavarría, J. 1963a. Sección de sociología del desarrollo. Documento de trabajo del ILPES. Santiago: ILPES.

Medina Echavarría, J. 1963b. El desarrollo social de América Latina en la postguerra. Buenos Aires: Solar-Hachette.

Medina Echavarría, J. 1963c. La recepción de la sociología norteamericana. Anales de la Universidad de Chile 126: 93-115.

Medina Echavarría, J. 1970. Los supuestos políticos de una crisis económica. En: ILPES. Dos polémicas sobre el desarrollo en América Latina. Santiago de Chile: Textos del ILPES, Editorial Universitaria, pp. 197-207.

Medina Echavarría, J. 1971. La planeación en las formas de racionalidad. Cuadernos del ILPES Serie II, Anticipos de Investigación 13.

Medina Echavarría, J. 1973. Aspectos sociales del desarrollo económico. Santiago de Chile: Serie conmemorativa del XXV aniversario de la CEPAL.

Medina Echavarría, J. 1976. Consideraciones sociológicas sobre el desarrollo económico en América Latina. San José: Editorial Universitaria Centroamericana.

Medina Echavarría, J. 1982. Sociología: teoría y técnica. México: Fondo de Cultura Económica. 
Prebisch, R. 1982. Intervenciones en el acto de homenaje a Don José Medina Echavarría. En: F. H. Cardoso, E. Faletto, J. Graciarena (et al.). Medina Echavarría y la sociología latinoamericana. Madrid: Ediciones Cultura Hispánica, Instituto de Cooperación Iberoamericana, pp. 15-18.

Rego, J. M. 2007. Entrevista com Enzo Faletto. Tempo Social 19(1): 189-213.

Reyna, J. L. 2007. Enzo Faletto (1935-2003): un intelectual latinoamericano. Recuerdos de la FLACSO: 1-5.

Solari, A; Franco, R. y Jutkowitz, J. 1976. Teoría, acción social y desarrollo en América Latina. México: ILPES, Siglo XXI.

Recibido el 12 Jun 2012

Aceptado el 4 Sep 2012 